\title{
The Role of Instagram, Facebook, and YouTube Frequency of Use in University Students' Digital Skills Components
}

\author{
Maria Perifanou, Katerina Tzafilkou and Anastasios A. Economides *(D) \\ SMILE Lab, University of Macedonia, 54636 Thessaloniki, Greece; mariaperif@gmail.com (M.P.); \\ katerinatzaf@gmail.com (K.T.) \\ * Correspondence: economid@uom.gr
}

Citation: Perifanou, M.; Tzafilkou, K.; Economides, A.A. The Role of Instagram, Facebook, and YouTube Frequency of Use in University Students' Digital Skills Components. Educ. Sci. 2021, 11, 766. https:// doi.org/10.3390/educsci11120766

Academic Editor: Margus Pedaste

Received: 30 October 2021

Accepted: 22 November 2021

Published: 28 November 2021

Publisher's Note: MDPI stays neutral with regard to jurisdictional claims in published maps and institutional affiliations.

Copyright: (c) 2021 by the authors. Licensee MDPI, Basel, Switzerland. This article is an open access article distributed under the terms and conditions of the Creative Commons Attribution (CC BY) license (https:/ / creativecommons.org/licenses/by/ $4.0 /)$.

\begin{abstract}
The literature provides rich evidence on students' levels of digital skills as well as on their frequency of Internet and social media use. Several studies have examined the relationships between social media use and academic achievement. However, there are not any studies investigating the relationships between social media use and digital skills of higher education students. To fill this research gap, this study examines the links between the frequency of social media use and students' digital skills. The survey was conducted with 155 university students in Greece. The instrument on six digital skills components was evaluated in terms of reliability and consistency. The research findings reveal a strong positive association between the use of YouTube and students' digital skills on content evaluation and protection. Age and educational level differences were noted in several digital skills components, whereas age and gender were related to the frequency of Instagram use. The main conclusion is that the generic use of Facebook and Instagram does not affect students digital skills. However, combined literature evidence implies that when social media are used for educational purposes, they might influence students' perceived levels of digital skills. Implications and limitations are discussed in the study.
\end{abstract}

Keywords: digital competence; digital skills; Facebook; Instagram; social media use; university students; YouTube

\section{Introduction}

The emergent situation due to the COVID-19 pandemic exhibited the necessity of social media and digital skills. People in quarantine need to use digital technologies (including social media) in order to communicate, work, shop, learn, be informed, socialize, have fun, and live their lives in general. For example, in the USA, about one third of adults had an online socializing event with friends or family and one third of adults ordered food online from a local restaurant during COVID-19 [1]. Similarly, there was a 35\% increase in using social media [2].

It is well known that social media give people opportunities for communication [3]; sharing information, experiences, knowledge, and emotions [4,5]; learning [6,7]; building relationships [8,9]; reputation management [10-12]; public participation and active citizenship [13-15]; and emergency and crisis management [16-18], among others. However, users of social media also face risks such as fake news and disinformation [15,19-22], polarization [23-25], bullying and harassment [26,27], and addiction [28,29], among others.

As of October 2020, there were over 4.5 billion active Internet users and over 4 billion active social media users worldwide. Specifically, there were more than 2.7 billion Facebook users, 2 billion YouTube users, 2 billion WhatsApp users, 1 billion Instagram users, 0.4 billion Pinterest users, and 0.3 billion Twitter users worldwide [30]. In Europe, over half of adults and $86 \%$ of young people 16 to 24 years old participated in social networks. According to Datareportal [31], on average Internet users spent from $1.3 \mathrm{~h}$ (in Japan, Germany, and France) to $4.5 \mathrm{~h}$ (in Brazil) on social media daily. They spent daily about $5 \mathrm{~h}$ on 
the Internet, of which about 1.5-2.0 $\mathrm{h}$ were on social media. On average worldwide, people spent over $2 \mathrm{~h}$ on social media daily [30].

However, even if someone uses social media intensively, that does not imply that he/she also has high digital skills. In Europe, Internet users correspond to $85 \%$ of all individuals 16 to 74 years old, and $97 \%$ of all individuals 16 to 25 years old. Among these Internet users, $65 \%$ use social media; $81 \%$ listen to music, play games, and watch videos; $66 \%$ do Internet banking (66\%); and 71\% e-shop. However, over $42 \%$ of Europeans between 16 and 74 years old do not have basic digital skills, and $40 \%$ of companies have difficulties recruiting ICT specialists [32]. Actually, only 58\% of Europeans have at least basic digital skills and $33 \%$ of Europeans have above basic digital skills.

As society and economy increasingly depend on digital technologies, they need to develop citizens and labor forces with digital skills [33]. Changes in all societal areas such as life (e.g., digital communication, entertainment, shopping, banking), education (e.g., online courses, digital school, digital educational resources, digital research), citizenship (participation, e-government), health (e.g., digital health), work/employment, business (e-entrepreneurship, digital marketing, e-commerce, digital business), etc., have brought up the need for all people to have digital skills. Digital technologies are used in all economic sectors, such as finance, commerce, construction, industry, energy, utilities, transportation, safety, healthcare, education, housing, agriculture, etc. It is estimated that $90 \%$ of jobs will require digital skills [34]. The connection between digital skills and employment has been documented by various studies [34-37]. Thus, the European Council Recommendation [38], the European Commission's Digital Education Action Plan [39], the Berlin Declaration [40], and the Digital Skills and Jobs Coalition [41] aim at developing the digital skills of students, citizens, and workers.

However, it is not universally accepted what digital skills comprises [42,43]. The European Training Foundation [44] and the European Council Recommendation [38] defined basic digital skills to include information and data literacy, online communication and collaboration, digital content creation, safety, intellectual property issues, and problem solving. So, an individual with basic digital skills can retrieve, assess, store, produce, present, and exchange information, and communicate and participate in collaborative virtual networks and social media using digital technologies. The DigComp 2.x framework $[45,46]$ describes digital competence across five areas: (i) information and data literacy, (ii) communication and collaboration, (iii) digital content creation, (iv) safety, and (v) problem solving. UNESCO [33] describes digital skills on three levels: (i) basic functional digital skills to use digital devices and access information and resources; (ii) generic digital skills including information literacy, communication and collaboration, digital content creation, digital safety, and digital rights; and (iii) higher-level skills including computer programming (coding) and computational thinking. Furthermore, the European Union Framework of Digital Competence of Educators_-DigCompEdu [47]—has been applied by several researchers [48] on the teacher populations since their digital competences are essential to guarantee the efficient transition of knowledge to their students and encourage teaching and learning innovation [49].

Although there is a lot of research both on social media use and on digital skills, as shown above, there is limited research investigating their interrelationships. Most previous studies investigate the effect of social media use on students' academic performance. Lambić [50] found a positive correlation between students' academic performance and their frequency of Facebook use for educational purposes but no correlation for general-purpose use. Similarly, Al-Rahmi [51] found that social media use by students positively affected their learning performance. However, Liu [52] found a significant negative relationship between the use of social media and academic performance. Similarly, other studies found that high social media use deteriorates students' academic performance [53-55]. More specifically, Wakefield [56] found that increasing Facebook use decreases the performance of lower academic achievers across the least difficult levels of learning performance, but does not have a significant effect on higher academic achievers. 
Correspondingly, when investigating the relationship of Facebook use and educational level, Van Deursen [57] found that people with low levels of education were using the Internet for more hours daily in their spare time than higher educated and employed people. Similarly, Correa [58] found that lower educated young people tended to use Facebook more frequently. She also found that digital skills were not related to the frequency of Facebook use. However, according to Pew Research Center [1], the more educated the person, the more they tend to use social media. More adults with a college degree or more (74\%) use Facebook than those with a high school diploma or less (61\%). Finally, Castillo de Mesa [59] investigated the moderating effect of digital skills on the relationship between closeness and resilience in a Facebook group. They found that participants' cohesion increased their resilience capacity when digital skills were high.

Motivated by the above-mentioned research gaps, this paper will investigate the following three main research questions (RQ):

RQ1: Are there any significant correlations between social media use and digital skills?

RQ2: Are there any significant differentiations in social media use according to students' gender, age, grade, and educational level?

RQ3: Are there any significant differentiations in digital skills according to students' gender, age, grade, and educational level?

In this research, the term "digital skills" is described by six components reflecting the students' digital skills to (1) Communicate, Collaborate, Share; (2) Search, Find, Access; (3) Store, Manage, Delete; (4) Evaluate; (5) Protect; and (6) Develop, Apply, Modify, as presented in Perifanou [60,61]. The term "social media use" is defined by the frequency (hours per week) of students' use of three popular social media networks: Instagram, Facebook, and YouTube. This study aims to investigate the bivariate correlations between each network and the students' digital skills components.

\section{Methodology}

\subsection{Context of Study: Greece}

This study was implemented in Greece. According to ELSTAT [62], Greece has a population of around 10.7 million people. In 2017-2018, there were 190,000 university students. In $2019,75.7 \%$ of the population aged 16-74 years were accessing the Internet (i.e., $77.9 \%$ for sending/receiving emails, $66.8 \%$ for telephoning over the Internet, $74.9 \%$ for social networking, $88.3 \%$ for finding information about goods and services, $87.7 \%$ for reading/downloading newspapers and magazines, $65.9 \%$ for finding information or using health-related services, $40.3 \%$ for Internet banking, $64.6 \%$ for obtaining information from public authority websites, $39.9 \%$ for downloading official forms, and $36.5 \%$ for sending filled-in forms). In addition, almost all young Greeks 16 to 24 years old were regular Internet users.

In Greece, there were 8.3 million Internet users and 6.2 million social media users in January 2020 [63]. There were 5.2 million Facebook users, 3.3. million Instagram users, 0.7 million Twitter users, and 1.6 million LinkedIn users.

Regarding the use of social media by young Greeks 16 to 24 years old, 92.2\% of them participated in social networks (creating a user profile; posting messages or other contributions to Facebook, Twitter, etc.) over the Internet in the last three months [64]. The most popular social media was Facebook (82.84\%), followed by Pinterest $(9.84 \%)$, Twitter $(2.72 \%)$, Instagram (2.14\%), and YouTube (1.75\%) [65].

Regarding the digital skills of young Greeks 16 to 24 years old, $44.9 \%$ of them had an above basic level of digital skills, $92.3 \%$ of them had at least basic digital skills, and 35.1\% of them had a low level of digital skills (missing some type of basic skills) [64].

\subsection{Participants and Procedure}

A questionnaire and a consent form were distributed to 300 undergraduate and postgraduate students between January and April 2020. A written form of the questionnaire was provided to students of two different undergraduate courses (e-Commerce and e- 
Business, Information Systems in Management) in a university in Greece, and an online version of the same questionnaire was administered in three postgraduate programs (Information Systems, e-Business and Digital Marketing, Law and Economics) in Greece.

The questionnaire items about digital skills were measured on a five-point Likert scale (1: strongly disagree to 5 : strongly agree). The questionnaire also asked for information on the social and academic profile of the students (gender, age, average grade in last semester).

A total of 155 students (79 undergraduates and 76 postgraduates) voluntarily and anonymously completed the questionnaire, providing valid data (outliers were cleaned) and replying to all the items regarding digital skills components. Of those, 138 provided feedback regarding the frequency (hours per week) of Facebook use, 122 replied on Instagram, and 108 on YouTube. Table 1 presents the participants' socio-demographic profile.

Table 1. Participants' socio-demographic characteristics $(\mathrm{N}=154)$.

\begin{tabular}{|c|c|c|c|c|c|c|c|}
\hline Gender & $n \%$ & Age & $n \%$ & Study Program & $n \%$ & $\begin{array}{c}\text { Average Grade in Last } \\
\text { Semester }\end{array}$ & $n \%$ \\
\hline Female & $56.1 \%$ & $18-24$ & $59 \%$ & e-Commerce and e-Business (undergraduate) & $14.7 \%$ & 6.00 & $22.2 \%$ \\
\hline Male & $43.2 \%$ & $25-35$ & $29.5 \%$ & $\begin{array}{c}\text { Information Systems in Management } \\
\text { (undergraduate) }\end{array}$ & $36.5 \%$ & 7.00 & $61.1 \%$ \\
\hline \multirow[t]{4}{*}{$\mathrm{N} / \mathrm{A}$} & $0.6 \%$ & $36-45$ & $7.1 \%$ & e-Business and Digital Marketing (postgraduate) & $14.1 \%$ & 8.00 & $8 / 3 \%$ \\
\hline & & $46-55$ & $2.6 \%$ & Law and Economics (postgraduate) & $8.9 \%$ & 9.0 & $0.0 \%$ \\
\hline & & $55+$ & $1.9 \%$ & Information Systems (postgraduate) & $19.2 \%$ & 10.00 & $2.8 \%$ \\
\hline & & & & Undefined & $6.4 \%$ & $\mathrm{~N} / \mathrm{A}$ & $5.6 \%$ \\
\hline
\end{tabular}

\subsection{Instrument Description and Evaluation}

A 28-item instrument was designed based on the modern digital skills components presented in Perifanou $[60,61]$. The suggested digital skills extend previous models by including items related to the newly emerged technological trends like social media and mobile use. The instrument was composed of 6 components measuring the students' digital skills to (1) Communicate, Collaborate, Share; (2) Search, Find, Access; (3) Store, Manage, Delete; (4) Evaluate; (5) Protect; and (6) Develop, Apply, Modify. The structure of the instrument and the items' wording are presented in Appendix A.

The instrument was evaluated in terms of reliability, internal consistency, and convergence validity. The evaluation was applied through a partial least square (PLS) confirmatory factor analysis (CFA) approach in the SmartPLS software. As depicted in Table 2, all the values of Cronbach's alpha and composite reliability (CR) demonstrated internal consistency $(>0.7)$. The convergence validity was evaluated through average variance extracted (AVE) that met accepted values, above the threshold of 0.7 [66] in all components. In addition, the item-total correlations were examined, and significant correlations were shown to exist between the factors $(p<0.01)$.

Table 2. Constructed reliability and validity of the measured digital skills components.

\begin{tabular}{cccc}
\hline Reliability Statistics: CA & $\begin{array}{c}\text { Cronbach's } \\
\text { Alpha }\end{array}$ & $\begin{array}{c}\text { Composite } \\
\text { Reliability }\end{array}$ & $\begin{array}{c}\text { Average Variance } \\
\text { Extracted (AVE) }\end{array}$ \\
\hline Communicate, Collaborate, & 0.760 & 0.862 & 0.677 \\
Share (CCS) & 0.784 & 0.853 & 0.537 \\
Search, Find, Access (SFA) & 0.792 & 0.857 & 0.546 \\
Store, Manage, Delete (SMD) & 0.863 & 0.898 & 0.594 \\
Evaluate (EV) & 0.703 & 0.835 & 0.628 \\
Protect (PR) & 0.819 & 0.867 & 0.524 \\
\hline
\end{tabular}

\subsection{Data Analysis}

The results of the normal distribution tests revealed non normality $(p<0.05)$ for all the measured variables across all examined groups. For this reason, we used non-parametric 
statistics to explore bivariate correlations and group-based differences in the measured constructs. In particular, the Spearman Rho correlation test was applied to examine the significant correlations between the frequency of social media use and digital skills. Gender and educational-level differences were examined through the Mann-Whitney Test, whereas differences in multi-level variables like age and grade were evaluated through the Kruskal-Wallis test. IBM SPSS software was used for the descriptive statistics and the statistical tests.

\section{Results}

3.1. Descriptive Statistics Regarding Social Media Use and Digital Skills

As shown in Table 3 YouTube was the most frequently used social media network amongst Greek students. The students also spent less time (on a weekly rate) on Facebook compared to Instagram. The high values in the standard deviations reveal the students individual differences in their expressed frequency of social media use.

Table 3. Descriptive statistics of social media use for Instagram, Facebook, and YouTube.

\begin{tabular}{cccccc}
\hline $\begin{array}{c}\text { Social Media Use Frequency } \\
\text { (Hours/Week) }\end{array}$ & $\mathbf{N}$ & Minimum & Maximum & Mean & Std. Deviation \\
\hline Instagram & 122 & 1.0 & 65 & 12.65 & 11.165 \\
Facebook & 138 & 1.0 & 70.0 & 7.856 & 9.0987 \\
YouTube & 108 & 1.0 & 100 & 13.94 & 12.850 \\
\hline
\end{tabular}

As shown in Table 4, students expressed high levels of digital skills in most of the examined components. However, the component of DAM received the lowest mean score $(<3.0)$.

Table 4. Descriptive statistics of digital skills components $(\mathrm{N}=155)$.

\begin{tabular}{ccccc}
\hline Digital Skills Components & Minimum & Maximum & Mean [1, 5] & Std. Deviation \\
\hline CCS & 1.33 & 5.00 & 4.3571 & 0.62982 \\
SFA & 2.40 & 5.00 & 4.2987 & 0.59683 \\
SMD & 2.40 & 5.00 & 4.5143 & 0.53473 \\
EV & 1.67 & 5.00 & 3.9593 & 0.74776 \\
PIM & 1.00 & 5.00 & 4.0633 & 0.75654 \\
DAM & 1.00 & 5.00 & 2.7958 & 0.88731 \\
\hline
\end{tabular}

\subsection{Correlations between Social Media Use and Digital Skills}

Table 5 presents the results of the Spearman Rho correlation test. A set of significant correlations was detected between the frequency of YouTube use and two digital skills components, EV and PR. The frequency of use of other networks (Instagram and Facebook) did not reveal any significant correlations in the examined sample. 
Table 5. Spearman correlation results between social media use and digital skills.

\begin{tabular}{|c|c|c|c|c|c|c|c|}
\hline Soc & Media Use & CCS & SFA & SMD & EV & PR & DAM \\
\hline \multirow{3}{*}{ Instagram } & $\begin{array}{c}\text { Correlation } \\
\text { coefficient }\end{array}$ & 0.010 & 0.115 & 0.084 & 0.125 & 0.020 & 0.023 \\
\hline & Sig. (2-tailed) & 0.916 & 0.208 & 0.359 & 0.169 & 0.827 & 0.805 \\
\hline & $\mathrm{N}$ & 122 & 122 & 122 & 122 & 122 & 122 \\
\hline \multirow{3}{*}{ Facebook } & $\begin{array}{l}\text { Correlation } \\
\text { coefficient }\end{array}$ & -0.087 & -0.006 & 0.010 & 0.022 & 0.058 & 0.045 \\
\hline & Sig. (2-tailed) & 0.312 & 0.942 & 0.906 & 0.798 & 0.502 & 0.603 \\
\hline & $\mathrm{N}$ & 138 & 138 & 138 & 138 & 138 & 138 \\
\hline \multirow{3}{*}{ YouTube } & $\begin{array}{c}\text { Correlation } \\
\text { coefficient }\end{array}$ & 0.094 & 0.182 & 0.171 & $0.278^{* *}$ & $0.258^{* *}$ & 0.162 \\
\hline & Sig. (2-tailed) & 0.331 & 0.060 & 0.076 & 0.004 & 0.007 & 0.093 \\
\hline & $\mathrm{N}$ & 108 & 108 & 108 & 108 & 108 & 108 \\
\hline
\end{tabular}

3.3. Differences in Social Media Use and Digital Skills According to the Students' Gender, Age, Grade, and Educational Level

\subsubsection{Differences in Social Media Use}

Significant group-based differences in social media use were observed for Instagram in the gender and age-related groups. Female students revealed significantly higher values of frequency use of Instagram, whereas no differences were detected in the use of Facebook or YouTube.

Instagram use revealed age-related differences as well, where the youngest groups (18-24, 25-35) expressed significantly higher values of frequency of use and the third age group (36-45) revealed the lowest ones.

On the other hand, differences in the frequency of Facebook use were detected between undergraduate and postgraduate students, where postgraduate students expressed significantly higher values of frequency use.

No differences were detected in relation to the students' grades.

Table 6 below shows the Mann-Whitney and Kruskal-Wallis results for the examined social media constructs across gender, age, and educational level-related groups.

Table 6. Significant differences in social media use in gender and age-related groups.

\begin{tabular}{|c|c|c|c|}
\hline Frequency Use & Instagram & Facebook & YouTube \\
\hline \multicolumn{4}{|c|}{ Grouping Variable: Gender } \\
\hline Mann-Whitney U & 1323.000 & 2191.000 & 1390.000 \\
\hline Wilcoxon W & 2649.000 & 5041.000 & 2768.000 \\
\hline $\mathrm{Z}$ & -2.538 & -0.583 & -0.408 \\
\hline Asymp. Sig. (2-tailed) & $0.011 *$ & 0.560 & 0.683 \\
\hline \multicolumn{4}{|c|}{ Grouping Variable: Age } \\
\hline Chi-square & 13.568 & 6.196 & 9.136 \\
\hline $\mathrm{df}$ & 4 & 4 & 4 \\
\hline Asymp. Sig. & 0.009 * & 0.185 & 0.058 \\
\hline \multicolumn{4}{|c|}{ Grouping Variable: Educational Level (Undergraduate/Postgraduate) } \\
\hline Mann-Whitney U & 1448.000 & 1726.500 & 1210.500 \\
\hline Wilcoxon W & 2673.000 & 3806.500 & 1990.500 \\
\hline Z & -1.784 & -2.864 & -0.982 \\
\hline Asymp. Sig. (2-tailed) & 0.074 & $0.004^{*}$ & 0.326 \\
\hline
\end{tabular}

* Correlation is significant at the 0.05 level (2-tailed).

\subsubsection{Differences in Digital Skills Components}

Significant group-based differences were observed in two digital skills components in relation to age, and in four components in relation to educational level. Gender and grade revealed no significant differences. 
In particular, students between 24 and 35 years old expressed the highest values in PR and DAM digital skills. The youngest group (18-24) expressed the lowest values in PR, whereas the oldest groups $(46-55,55+)$ expressed the lowest values in DAM.

Furthermore, postgraduate students expressed significantly higher values than undergraduate students in the components of CCS, EV, PR, and DAM. Table 7 below presents the Kruskal-Wallis results for the examined digital skills components across age and educational level-related groups.

Table 7. Significant differences in digital skills components in age and educational level-related groups.

\begin{tabular}{|c|c|c|c|c|c|c|}
\hline & CCS & SFA & SMD & EV & PR & DAM \\
\hline \multicolumn{7}{|c|}{ Grouping Variable: Age } \\
\hline Chi-square & 6.018 & 9.054 & 7.692 & 7.807 & 10.265 & 10.833 \\
\hline $\mathrm{df}$ & 4 & 4 & 4 & 4 & 4 & 4 \\
\hline Asymp. Sig. & 0.198 & 0.060 & 0.104 & 0.099 & $0.036^{*}$ & 0.029 * \\
\hline \multicolumn{7}{|c|}{ Grouping Variable: Educational Level (Undergraduate/Postgraduate) } \\
\hline $\begin{array}{c}\text { Mann-Whitney } \\
\text { U }\end{array}$ & 2371.500 & 2582.000 & 2493.500 & 2340.500 & 2044.000 & 2175.000 \\
\hline Wilcoxon W & 5531.500 & 5742.000 & 5653.500 & 5500.500 & 5204.000 & 5335.000 \\
\hline $\mathrm{Z}$ & -2.306 & -1.516 & -1.858 & -2.374 & -3.452 & -2.967 \\
\hline $\begin{array}{l}\text { Asymp. Sig. } \\
\text { (2-tailed) }\end{array}$ & 0.021 * & 0.129 & 0.063 & $0.018 *$ & 0.001 * & $0.003 *$ \\
\hline
\end{tabular}

* Correlation is significant at the 0.05 level (2-tailed).

\section{Discussion and Implications}

This research study revealed several interesting findings about the role of popular social media networks (in terms of frequency use) and the students' digital skills across six digital skills components. Furthermore, some remarkable outcomes emerged in terms of group-based differences according to the students' gender, age, and educational level.

As shown in Table 4, the students expressed high levels of digital skills in most of the examined components, implying that they are quite confident to Communicate, Collaborate, Share; Search, Find, Access; Store, Manage, Delete; Evaluate; and Protect using digital technologies. These findings are in accordance with recent evidence [64] supporting that young Greeks have at least basic digital skills. However, our findings suggest that young Greeks need to be further qualified in terms of development skills (Develop, Apply, Modify). In fact, developing skills were characterized as "advanced digital skills" by Cedefop [67], and hence, Cedefop suggests designing enhanced strategies to allow citizens access to further training since "advanced digital skills, in particular programming and coding, will become a key prerequisite for entry into many jobs" (as cited in Cedefop [67].

Next, we discuss the specific findings for the stated research objectives. RQ1: Are there any significant correlations between social media use and digital skills?

Our findings revealed significant correlations between social media use and digital skills only for the YouTube network. Facebook and Instagram use did not show any relationship with the students' digital skills. This finding is in accordance with previous studies like Correa [58], who found that digital skills are not related to the frequency of Facebook use. As already stated, there are not many studies exploring this relationship since most previous studies targeted the relationship between Facebook use and students academic achievement.

The reason that YouTube is linked (in this study) to students' digital skills might be explained by that social network's characteristics compared those of Facebook or Instagram. As explained in Bhatia [68], YouTube has emerged as an informal learning environment where users can access a huge dataset of video tutorials and how-to-related material. Researchers have pointed out that university students tend to visit YouTube regularly to learn how to solve specific problems [69]. In previous years, YouTube was recognized as a significant source of educative material for several study disciplines, especially nursing and 
medicine [70]. Today, researchers agree that YouTube is a rich source of online educational videos that effectively affect students' learning [71].

So, all the above imply that students tend to use YouTube to seek information (either on educational content or otherwise), which can positively affect their learning. Therefore, this seems to be the main reason why YouTube is positively associated with students' digital skills. Interestingly, in this study the frequency of YouTube use was positively associated with the digital skills of Evaluate and Protect, implying that the higher the frequency of watching YouTube videos the higher the students' skills and efficiency in identifying trusted and non-trusted web content, malicious attacks, or fake information and protecting themselves. A reasonable explanation might be Europe's recent attempts on cybersecurity awareness [72] or the recent era of the \#MeToo movement and online harassment [73], which may motivate individuals to seek relevant information in the YouTube databases. RQ2: Are there any significant differentiations in social media use according to students' gender, age, grade, and educational level?

Both gender and age revealed significant differences in the frequency of Instagram use, but not of Facebook or YouTube. Regarding gender, female students expressed higher values of Instagram use compared to male students. This result aligns well with Statista's [74] recent findings that there are more female Instagram users than male ones. Previous research has also proven gender differences in online activities and social media preferences [75-77]; however, females' favored medium was not stated. As explained in Van Deursen [57], women use social media for communication, text messaging, and video calls more often than men. On the other hand, authors have shown that male users access social media mainly to seek information and read news, make commercial transactions, for entertainment reasons, or for personal development. All the above do not clearly explain the significant difference between Instagram and Facebook, since they share the main core characteristics compared to YouTube (or other networks, e.g., Twitter). We believe it is the network's photo-centric characteristics that might render it more favorable to the female population. However, it might be the combination of gender and age that rendered this outcome. According to Statista [78], as of January 2021 most Instagram users were young females (18-34). This is also confirmed by the age-related results of our study that demonstrated that the youngest groups expressed significantly higher values in the frequency of Instagram use. However, by examining our sample characteristics we observed that there were more young females in the groups of 18-24 and 25-35 years old than young males. Therefore, we suggest future research to re-examine the statistical significance of gender differences in the frequency of Instagram use.

Contrary to previous findings showing that academic or learning performance is related to the frequency of social media use [51-55], our research revealed no effect of students' average grade. Our finding can be explained by the fact that we measured the students' generic use of social media without trying to identify their learning-related activities on social media. According to the findings of Lambić [50], a correlation between students' academic performance and their frequency of Facebook use was detected only in their use for educational purposes and not in general.

The increased frequency of Facebook use that was observed in postgraduate students aligns well with the previous study by Pew Research Center [1], who found out that adults with a college degree or more use Facebook more frequently than those with a high school diploma. However, more research needs to be done since our study was focused on undergraduate and postgraduate students and not on the generic population.

RQ3: Are there any significant differentiations in digital skills according to students' gender, age, grade, and educational level?

No gender- or grade-related differences were detected in the measured digital skills components. Age revealed significant group differences in two components (PR and DAM), and educational level revealed significant group differences in four (CCS, EV, PR, and DAM) out of six components. 
Contrary to previous studies [79], this study did not detect any gender gap in the students' digital skills, since both female and male students expressed relatively equal mean scores even in advanced digital skills like developing (DAM). These findings are encouraging for the future of the gender gap elimination in computing; however, further research should be conducted due to the current participants' characteristics. For example, the overall descriptive statistics (Table 4) revealed a lower level of developing skills for the whole sample. This might suggest that other factors should be considered, such as, for instance, the participants' field of study of prior experience in developing tasks.

As regards age, we observed that the youngest group of 18-24 years old revealed the lowest score in protection skills (PR), whereas the group of 24-35 years old revealed the highest ones both in PR and in DAM.

The educational-level difference in four digital skills components can possibly be explained by the fact that students in postgraduate programs have greater knowledge and practical experience in technology and hence express higher values of digital skills. However, this could vary according to the study field and prior experience; hence, further research is suggested.

\section{Research Implications and Limitations}

A first implication of this work is that students and instructors would be further motivated to use YouTube for educational reasons since it is positively associated with digital skills components. As suggested in previous research [71], students and educators should carefully evaluate the quality of YouTube videos to be used as educational material and educators should carefully check for the quality of the videos before suggesting them as supplementary learning materials.

A second implication is the adoption of Facebook and Instagram in the educational context as well. Since students tend to engage strongly and spend a lot of time on those networks as well, educators could encourage their students to enhance their knowledge on the course topics through those networks. For example, educators can cultivate a connectivity approach in learning by assigning students to Facebook groups or asking them to create content and upload photo-based material to Instagram, especially for complex educational concepts that are better explained through visualized representations (e.g., in medicine courses [80]). Moreover, Instagram can be used by students and educators to share useful information and build trusted communities where affective support is also provided. Researchers [81] have already suggested that the visual-centric nature of Instagram renders it a platform that invites personal disclosure and generates feelings of connectedness. Moreover, the significant difference in gender preferences implies that gender-oriented and personalized approaches could be implemented. For instance, young female students could be encouraged by educators to participate more in Instagram-related activities, since that platform seems to engage them more than others (Facebook).

Another implication is the need for cybersecurity awareness and protection practices among young students (18-24 years old). Young students should be more informed on how to protect themselves online, for example, by frequently changing their password, keeping their transactions secure, and being well-informed about protection strategies against bulling and harassment in social media.

Last, the age- and educational level-related differences in developing digital skills should be further considered so educators and educational institutions can design policies and practices to shrink the gaps and provide those groups of students with further training and support to enhance their digital skills.

This research has some limitations. First, the survey was based on self-reported feedback and not on actual measures, so there might be critical differentiations in the frequency of social media use expressed by the students. Another limitation relates to generalizability and the student population. All the participants were attending Greek universities and did not differ significantly in terms of educational background. Finally, the sample size was quite small, and which could have led to some bias in the results. 


\section{Conclusions and Future Research}

Although there is rich literature on the use of social media among young adults and on their digital skills, no research evidence exists on the relationships between those constructs. To this end, we examined the relationship between the frequency use of three popular social media networks (Instagram, Facebook, and YouTube) and students' digital skills, as well as their group-based differences according to their gender, age, grade, and educational level.

In this study we measured students' digital skills in accordance with six digital skills components as derived from recent literature. Our findings revealed a set of significant findings, especially on the role of YouTube. A strong positive correlation was found between the frequency of YouTube use and students' digital skills regarding their evaluation and protection skills. This finding raised several concerns regarding the adoption and use of YouTube as a formal educational channel in higher education.

Another interesting finding was the gender and age-related differences that were observed in the frequency of Instagram use as well as the age-related differences observed in two digital skills components. Although the students' grades did not reveal any significant outcome, the educational level (undergraduate/postgraduate) yielded several significant differentiations in the digital skills components as well as in the frequency of Facebook use.

The findings of this study have some limitations, and hence future research should be conducted. For instance, despite the generalizability limitation, these findings could contribute to specific trends in population groups, and hence more studies should be conducted to compare the results in different populations. Moreover, our findings can be extended by future research that will investigate older adults' social media use and digital skills as well as the inequalities with respect to Internet-access infrastructure and use of different social media networks (e.g., TikTok, Snapchat, LinkedIn, Twitter, Pinterest).

Overall, our findings seek to contribute to the deeper understanding of the differentiations and links between social media used and digital skills in university students.

Author Contributions: Conceptualization, M.P. and A.A.E.; methodology, M.P., K.T. and A.A.E.; software, K.T.; validation, M.P. and K.T.; formal analysis, M.P. and K.T.; investigation, M.P. and K.T.; resources, M.P., K.T. and A.A.E.; data curation, K.T.; writing-original draft preparation, M.P. and K.T.; writing-review and editing, M.P., K.T. and A.A.E.; supervision, A.A.E.; project administration, A.A.E. All authors have read and agreed to the published version of the manuscript.

Funding: This research received no external funding.

Institutional Review Board Statement: Not applicable.

Informed Consent Statement: Informed consent was obtained from all subjects involved in the study.

Data Availability Statement: All data that are not subjected to institutional restrictions are available within the manuscript.

Conflicts of Interest: The authors declare no conflict of interest. 


\section{Appendix A}

Table A1. Digital skills instrument.

\begin{tabular}{|c|c|c|c|}
\hline Component & Acronym & Items & Acronym \\
\hline \multirow{4}{*}{$\begin{array}{l}\text { 1. Communicate, } \\
\text { Collaborate, Share }\end{array}$} & CCS & & \\
\hline & & $\begin{array}{c}\text { I can collaborate with people using various smart devices, platforms, and } \\
\text { digital tools. }\end{array}$ & CCS1 \\
\hline & & $\begin{array}{c}\text { I can teach an e-course or an e-seminar, give a lecture, or make a presentation } \\
\text { using various digital tools. }\end{array}$ & CCS2 \\
\hline & & $\begin{array}{c}\text { I can upload and share software or apps that I have developed on various } \\
\text { social media. }\end{array}$ & CCS3 \\
\hline
\end{tabular}

\section{Search, Find,}

Access
SFA

I can search for and find a specific object or similar objects using various search engines (e.g., Google, Yahoo, Bing) and databases, using appropriate keywords and advanced criteria and filters.

I can search for and find a specific person on various social networks using various techniques and filters (e.g., various formats of name, photo, email address, school, company, etc.).

I can search for and find groups on a specific topic (e.g., hobby, profession, artist, science, historical event, travel destination) on various social media.

I can navigate in the real world using the advanced features of a navigator.

I can watch (read, listen, view) content in various formats on various smart devices.

3. Store, Manage, Delete

SMD

I can take a photo or a video and save it in various formats (.mp4, .wmv, .avi, .qt, .gif, .jpg, etc.) using various smart devices and digital recording tools. I can download content and save it directly to the relevant folder. I can copy and save a screenshot from various smart devices.

I can delete some of my connections/friends on various social networks.

I can organize the files on my computer into a hierarchical folder structure.

EV

I can evaluate an object and/or a smart device using appropriate quality criteria (e.g., authenticity, utility, easy to use, appearance, functionality, enjoyment).

I can critique an object and/or a smart device on relevant social media (e.g., TripAdvisor, YouTube, Amazon).

I can evaluate whether some information is a hoax, fake, a scam, or a fraud. I can evaluate whether a website is secure and trusted.

I can identify the intellectual property rights (IPRs) of content that I have found on the Internet.

I can evaluate whether an email is spam, adware, phishing, or fraud.

5. Protect PR

I can regularly change my passwords and the settings of my smart devices and Internet accounts.

I can protect various smart devices and e-accounts using different passwords and frequently changing them.

I can protect myself and others against identity theft, harassment, bullying, or slander.

6. Develop, Apply, Modify

\section{DAM}

I can create an event and set notifications using a digital calendar (e.g.,

Google Calendar, Apple Calendar, Microsoft Outlook Calendar).

I can creatively design and/or develop a website using various digital tools (e.g., Wix, WordPress)

I can create a document with text, diagrams, tables, reports, and advanced formatting.

I can apply Creative Commons licenses to content or software that I have created.

I can apply statistical techniques using appropriate software (e.g., SPSS, R, MS Excel, Google Sheets) in order to make forecasts or predictions. 


\section{References}

1. Pew Research Center. Available online: https://www.pewresearch.org/ (accessed on 12 December 2020).

2. Nguyen, M.H.; Gruber, J.; Fuchs, J.; Marler, W.; Hunsaker, A.; Hargittai, E. Changes in digital communication during the COVID-19 global pandemic: Implications for digital inequality and future research. Soc. Media Soc. 2020, 6, 1-6. [CrossRef] [PubMed]

3. Gorska, A.; Korzynski, P.; Mazurek, G.; Pucciarelli, F. The role of social media in scholarly collaboration: An enabler of international research team's activation? J. Glob. Inf. Technol. Manag. 2020, 23, 273-291. [CrossRef]

4. Ahmed, Y.A.; Ahmad, M.N.; Ahmad, N.; Zakaria, N.H. Social media for knowledge-sharing: A systematic literature review. Telemat. Inform. 2019, 37, 72-112. [CrossRef]

5. Imran, M.K.; Iqbal, S.M.J.; Aslam, U.; Fatima, T. Does social media promote knowledge exchange? A qualitative insight. Manag. Decis. 2019, 57, 688-702. [CrossRef]

6. Mnkandla, E.; Minnaar, A. The use of social media in e-learning: A metasynthesis. Int. Rev. Res. Open Distrib. Learn. IRRODL 2017, 18, 227-248. [CrossRef]

7. Moghavvemi, S.; Sulaiman, A.; Jaafar, N.I.; Kasem, N. Social media as a complementary learning tool for teaching and learning: The case of YouTube. Int. J. Manag. Educ. 2018, 16, 37-42. [CrossRef]

8. Abeza, G.; O'Reilly, N.; Seguin, B. Social media in relationship marketing: The perspective of professional sport managers in the MLB, NBA, NFL, and NHL. Commun. Sport 2019, 7, 80-109. [CrossRef]

9. Wang, Y.; Yang, Y. Dialogic communication on social media: How organizations use Twitter to build dialogic relationships with their publics. Comput. Hum. Behav. 2020, 104, 106183. [CrossRef]

10. Chung, S.; Cho, H. Fostering parasocial relationships with celebrities on social media: Implications for celebrity endorsement. Psychol. Mark. 2017, 34, 481-495. [CrossRef]

11. Jacobson, J. You are a brand: Social media managers' personal branding and "the future audience". J. Prod. Brand Manag. 2020, 29, 715-727. [CrossRef]

12. Thompson, A.J.; Martin, A.J.; Gee, S.; Geurin, A.N. Building brand and fan relationships through social media. Sport Bus. Manag. Int. J. 2018, 8, 235-256. [CrossRef]

13. De Choudhury, M.; Jhaver, S.; Sugar, B.; Weber, I. Social media participation in an activist movement for racial equality. In Proceedings of the Tenth International AAAI Conference on Weblogs and Social Media, Cologne, Germany, 17-20 May 2016; AAAI: Palo Alto, CA, USA, 2016; pp. 92-101.

14. Gleason, B.; Von Gillern, S. Digital citizenship with social media: Participatory practices of teaching and learning in secondary education. J. Educ. Technol. Soc. 2018, 21, 200-212.

15. Valenzuela, S.; Halpern, D.; Katz, J.E.; Miranda, J.P. The paradox of participation versus misinformation: Social media, political engagement, and the spread of misinformation. Digit. J. 2019, 7, 802-823. [CrossRef]

16. Jin, Y.; Liu, B.F.; Austin, L.L. Examining the role of social media in effective crisis management: The effects of crisis origin, information form, and source on publics' crisis responses. Commun. Res. 2014, 41, 74-94. [CrossRef]

17. Luna, S.; Pennock, M.J. Social media applications and emergency management: A literature review and research agenda. Int. J. Disaster Risk Reduct. 2018, 28, 565-577. [CrossRef]

18. Panagiotopoulos, P.; Barnett, J.; Bigdeli, A.Z.; Sams, S. Social media in emergency management: Twitter as a tool for communicating risks to the public. Technol. Forecast. Soc. Chang. 2016, 111, 86-96. [CrossRef]

19. Apuke, O.D.; Omar, B. Fake news and COVID-19: Modelling the predictors of fake news sharing among social media users. Telemat. Inform. 2020, 56, 101475. [CrossRef]

20. Guess, A.; Nagler, J.; Tucker, J. Less than you think: Prevalence and predictors of fake news dissemination on Facebook. Sci. Adv. 2019, 5, eaau4586. [CrossRef] [PubMed]

21. Meel, P.; Vishwakarma, D.K. Fake news, rumor, information pollution in social media and web: A contemporary survey of state-of-the-arts, challenges and opportunities. Expert Syst. Appl. 2019, 153. [CrossRef]

22. Vicario, M.D.; Quattrociocchi, W.; Scala, A.; Zollo, F. Polarization and fake news: Early warning of potential misinformation targets. ACM Trans. Web TWEB 2019, 13, 1-22. [CrossRef]

23. Gillani, N.; Yuan, A.; Saveski, M.; Vosoughi, S.; Roy, D. Me, My echo Chamber, and I: Introspection on social media polarization. In Proceedings of the 2018 World Wide Web, Lyon, France, 23-27 April 2018; pp. 823-831. [CrossRef]

24. Lee, J.K.; Choi, J.; Kim, C.; Kim, Y. Social media, network heterogeneity, and opinion polarization. J. Commun. 2014, 64, 702-722. [CrossRef]

25. Schmidt, A.L.; Zollo, F.; Scala, A.; Betsch, C.; Quattrociocchi, W. Polarization of the vaccination debate on Facebook. Vaccine 2018, 36, 3606-3612. [CrossRef] [PubMed]

26. Mathew, B.; Dutt, R.; Goyal, P.; Mukherjee, A. Spread of hate speech in online social media. In Proceedings of the 10th ACM Conference on Web Science; ACM: New York, NY, USA, 2019; pp. 173-182.

27. Pater, J.A.; Kim, M.K.; Mynatt, E.D.; Fiesler, C. Characterizations of online harassment: Comparing policies across social media platforms. In Proceedings of the 19th International Conference on Supporting Group Work, Sanibel Island, FL, USA, 13-16 November 2016; pp. 369-374.

28. D'Arienzo, M.C.; Boursier, V.; Griffiths, M.D. Addiction to social media and attachment styles: A systematic literature review. Int. J. Ment. Health Addict. 2019, 17, 1094-1118. [CrossRef] 
29. Xuan, Y.J.; Amat, M.A.C. Social media addiction and young people: A systematic review of literature. J. Crit. Rev. $2020,7,537-541$.

30. Statista. Available online: https://www.statista.com/topics/1164/social-networks/ (accessed on 12 December 2020).

31. Datareportal. Digital 2020: Global Digital Overview. Time per Day Spent using the Internet. Available online: https:// datareportal.com/reports/digital-2020-global-digital-overview (accessed on 11 May 2021).

32. European Commission. The Digital Skills Gap in Europe. Available online: https://ec.europa.eu/digital-single-market/en/ news / digital-skills-gap-europe (accessed on 12 December 2020).

33. UNESCO. Working Group on Education: Digital Skills for Life and Work. Broadband Commission for Sustainable Development. Available online: https:/ / www.skillsforemployment.org/KSP/ (accessed on 12 December 2020).

34. Curtarelli, M.; Gualtieri, V.; Shater Jannati, M.; Donlevy, V. ICT for Work: Digital Skills in the Workplace; European Union: Luxembourg, 2016. [CrossRef]

35. Bejaković, P.; Mrnjavac, Ž. The importance of digital literacy on the labour market. Empl. Relat. Int. J. 2020, 42, 921-932. [CrossRef]

36. Leahy, D.; Wilson, D. Digital skills for employment. In IFIP Conference on Information Technology in Educational Management; Springer: Berlin/Heidelberg, Germany, 2014; pp. 178-189.

37. van Laar, E.; van Deursen, A.J.; van Dijk, J.A.; de Haan, J. Determinants of 21st-century skills and 21st-century digital skills for workers: A systematic literature review. SAGE Open 2020, 10. [CrossRef]

38. European Council Recommendation. Key Competences for Lifelong Learning; European Union: Louxembourg, 2019. [CrossRef]

39. European Commission. Digital Education Action Plan. Available online: https://ec.europa.eu/education/education-in-the-eu/ digital-education-action-plan_en (accessed on 12 December 2020).

40. Berlin Declaration. Berlin Declaration on Digital Society and Value-Based Digital Government. Available online: https://ec. europa.eu/digital-single-market/en/news/berlin-declaration-digital-society-and-value-based-digital-government (accessed on 12 December 2020).

41. Digital Skills and Jobs Coalition. Available online: https://ec.europa.eu/digital-single-market/en/digital-skills-jobs-coalition (accessed on 21 September 2019).

42. Pettersson, F. On the issues of digital competence in educational contexts-A review of literature. Educ. Inf. Technol. 2018, 23, 1005-1021. [CrossRef]

43. Spante, M.; Hashemi, S.S.; Lundin, M.; Algers, A. Digital competence and digital literacy in higher education research: Systematic review of concept use. Cogent Educ. 2018, 5. [CrossRef]

44. ETF. Digital Skills and Competence, and Digital and Online Learning, European Training Foundation. Available online: https:/ / www.etf.europa.eu/sites / default/files/2018-10/DSC\%20and\%20DOL_0.pdf (accessed on 12 December 2020).

45. DigComp. The Digital Competence Framework 2.0. Available online: https:// ec.europa.eu/jrc/en/digcomp/digital-competenceframework (accessed on 12 December 2020).

46. Carretero, S.; Vuorikari, R.; Punie, Y. DigComp 2.1. The Digital Competence Framework for Citizens. With Eight Proficiency Levels and Examples of Use; Publications Office of the European Union: Luxembourg, 2017.

47. Redecker, C.; Punie, Y. Digital Competence of Educators DigCompEdu; Publications Office of the European Union: Luxembourg, 2017. [CrossRef]

48. Cabero-Almenara, J.; Guillén-Gámez, F.D.; Ruiz-Palmero, J.; Palacios-Rodríguez, A. Digital competence of higher education professor according to DigCompEdu. Statistical research methods with ANOVA between fields of knowledge in different age ranges. Educ. Inf. Technol. 2021, 26, 4691-4708. [CrossRef]

49. Artacho, E.G.; Martínez, T.S.; Ortega Martín, J.L.; Marín Marín, J.A.; García, G.G. Teacher training in lifelong learning-the importance of digital competence in the encouragement of teaching innovation. Sustainability 2020, 12, 2852. [CrossRef]

50. Lambić, D. Correlation between Facebook use for educational purposes and academic performance of students. Comput. Hum. Behav. 2016, 61, 313-320. [CrossRef]

51. Al-Rahmi, W.M.; Alias, N.; Othman, M.S.; Marin, V.I.; Tur, G. A model of factors affecting learning performance through the use of social media in Malaysian higher education. Comput. Educ. 2018, 121, 59-72. [CrossRef]

52. Liu, D.; Kirschner, P.A.; Karpinski, A.C. A meta-analysis of the relationship of academic performance and Social Network Site use among adolescents and young adults. Comput. Hum. Behav. 2017, 77, 148-157. [CrossRef]

53. Junco, R. Too much face and not enough books: The relationship between multiple indices of Facebook use and academic performance. Comput. Hum. Behav. 2012, 28, 187-198. [CrossRef]

54. Junco, R. Student class standing, Facebook use, and academic performance. J. Appl. Dev. Psychol. 2015, 36, 18-29. [CrossRef]

55. Whelan, E.; Islam, A.N.; Brooks, S. Applying the SOBC paradigm to explain how social media overload affects academic performance. Comput. Educ. 2020, 143, 103692. [CrossRef]

56. Wakefield, J.; Frawley, J.K. How does students' general academic achievement moderate the implications of social networking on specific levels of learning performance? Comput. Educ. 2020, 144, 103694. [CrossRef]

57. Van Deursen, A.J.A.M.; Van Dijk, J.A.G.M.; Ten Klooster, P.M. Increasing inequalities in what we do online: A longitudinal cross sectional analysis of Internet activities among the Dutch population (2010 to 2013) over gender, age, education, and income. Telemat. Inform. 2015, 32, 259-272. [CrossRef]

58. Correa, T. Digital skills and social media use: How Internet skills are related to different types of Facebook use among 'digital natives'. Inf. Commun. Soc. 2016, 19, 1095-1107. [CrossRef] 
59. Castillo de Mesa, J.; Gómez Jacinto, L. Facebook groups as social intervention tools for improving digital skills. Soc. Work Educ. 2020, 39, 71-84. [CrossRef]

60. Perifanou, M.; Economides, A. An instrument for the digital competence actions framework. In Proceedings of the ICERI2019 Proceedings, Seville, Spain, 11-13 November 2019; Volume 1, pp. 11139-11145. [CrossRef]

61. Perifanou, M.; Economides, A. The digital competence actions framework. In Proceedings of the ICERI2019 Proceedings, Seville, Spain, 11-13 November 2019; Volume 1, pp. 11109-11116. [CrossRef]

62. ELSTAT. Hellenic Statistic Authority-Greece in Figures. Available online: https:/ /www.statistics.gr/greece-in-figures (accessed on 12 December 2020).

63. Digital 2020: Greece. Available online: https://datareportal.com/reports/digital-2020-greece?rq=greece (accessed on 12 December 2020).

64. Eurostat. Available online: https:/ / ec.europa.eu/eurostat/cache/infographs/youth/index_en.html (accessed on 11 May 2021).

65. StatCounter. Available online: https://gs.statcounter.com/social-media-stats (accessed on 12 December 2020).

66. Dijkstra, T.K.; Henseler, J. Consistent and asymptotically normal PLS estimators for linear structural equations. Comput. Stat. Data Anal. 2015, 81, 10-23. [CrossRef]

67. Cedefop. The great divide: Digitalisation and digital skill gaps in the EU workforce. In \#ESJsurvey Insights; No 9; Cedefop: Thessaloniki, Greece, 2016.

68. Bhatia, A. Interdiscursive performance in digital professions: The case of YouTube tutorials. J. Pragmat. 2018, 124, 106-120 [CrossRef]

69. Lim, W.Y.; Chew, Y.X.; Chan, C.Y.; Leow, S.K.; Mohamad Rozlan, S.B.; Yong, W.J. Students' acceptance of YouTube for procedural learning. In Handbook of Research on Leveraging Consumer Psychology for Effective Customer Engagement; IGI Global: Hershey, PA, USA, 2017; pp. 57-74. [CrossRef]

70. Duncan, I.; Yarwood-Ross, L.; Haigh, C. YouTube as a source of clinical skills education. Nurse Educ. Today 2013, 33, 1576-1580. [CrossRef] [PubMed]

71. Shoufan, A. Estimating the cognitive value of YouTube's educational videos: A learning analytics approach. Comput. Hum. Behav. 2019, 92, 450-458. [CrossRef]

72. ENISA. European Cybersecurity Month 2019 is Launched. Available online: https:/ /www.enisa.europa.eu/news/europeancybersecurity-month-2019-is-launched/ (accessed on 11 May 2021).

73. Atwater, L.E.; Sturm, R.E.; Taylor, S.N.; Tringale, A. The era of \#MeToo and what managers should do about it. Bus. Horiz. 2021, 64, 307-318. [CrossRef]

74. Statista. Distribution of Instagram Users Worldwide as of October 2021, by Gender. Available online: https: / www.statista.com/ statistics /802776/distribution-of-users-on-instagram-worldwide-gender/ (accessed on 15 November 2021).

75. Perifanou, M.; Economides, A.A. Gender digital divide in Europe. Int. J. Bus. Humanit. Technol. IJBHT 2020, 10, 7-14. [CrossRef]

76. Perifanou, M.; Economides, A.A. Gender gap in digital skills in Greece, Scientia Moralitas. Int. J. Multidiscip. Res. 2020, 5, 24-35. Available online: http:/ / www.scientiamoralitas.com/index.php/sm/article/view/71. (accessed on 15 April 2021).

77. Kovacevic, D.; Kascelan, L. Internet usage patterns and gender differences: A deep learning approach. IEEE Consum. Electron. Mag. 2020, 9, 105-114. [CrossRef]

78. Statista. Distribution of Instagram Users Worldwide as of January 2021, by Age and Gender. Available online: https: / www. statista.com/statistics/248769/age-distribution-of-worldwide-instagram-users / (accessed on 11 May 2021).

79. Grande-De-prado, M.; Cañón, R.; García-Martín, S.; Cantón, I. Digital competence and gender: Teachers in training. A case study. Future Internet 2020, 12, 204. [CrossRef]

80. Douglas, N.K.M.; Scholz, M.; Myers, M.A.; Rae, S.M.; Elmansouri, A.; Hall, S.; Border, S. Reviewing the role of Instagram in education: Can a photo sharing application deliver benefits to medical and dental anatomy education? Med. Sci. Educ. 2019, 29, 1117-1128. [CrossRef] [PubMed]

81. Carpenter, J.P.; Morrison, S.A.; Craft, M.; Lee, M. How and why are educators using Instagram? Teach. Teach. Educ. 2020, 96. [CrossRef] [PubMed] 